\title{
La crisis frente a la urgencia de acción crítica. Cenealogía de un problema del tiempo presente
}

\section{The crisis in front of the urgency of a critical action. Genealogy of a problem at present time \\ A crise diante da urgência da ação crítica. Genealogia de um problema do tempo presente}

Senda Sferco ${ }^{1}$

Recibido: 13 de julio de 2017 . Aceptado: 5 de septiembre de 2017

\begin{abstract}
Resumen
Los estudios filológicos clásicos confluyen en señalar que "crisis" proviene del vocablo griego «krisis», cuya raíz *krr es común a un cortejo de nociones que convocan las nociones de corte, de muerte, de redirección y jefatura. El estudio de este sustrato polimorfo ampliará la visión de la misma, e impedirá asentir a las explicaciones que, de la mano de la modernidad, asimilan la crisis a la figura de un movimiento reiterado e imponderable. Este análisis hará foco, en cambio, en la potencialidad de ruptura y de movimiento respecto de lo dado que en su base krisis trae consigo. Mediante un recorrido genealógico que se ocupará del tratamiento específico de esta noción en el saber médico de la Grecia clásica, la crisis será abordada poniendo en valor el "estatuto epistémico activo" habilitado por krisis cuando obliga a efectuar y a arriesgar una acción crítica. Dicho anacronismo probará su productividad frente a los desafíos heurísticos solicitados por las perspectivas de la filosofía política contemporánea, a la hora de reavivar el marco crítico de la crisis en nuestro tiempo presente.
\end{abstract}

Palabras clave: crisis y acción - temporalidad - estudios genealógicos filosofía política contemporánea - presentismo

1 Argentina, Doctora en Filosofía por la Universidad Nacional de Quilmes, Argentina. Investigadora de CONICET (Instituto de Investigaciones Gino Germani de la Universidad Nacional de Buenos Aires) y Docente de la Universidad Nacional del Litoral (UNL). Contacto: senda.sferco@gmail.com 


\begin{abstract}
Classical philological studies indicate that 'crisis' comes from the Greek word 'krisis,' which root *krr is common to several notions summoning concepts of cut, death, redirection and leadership. The study of this polymorphous substrate will broaden its vision and prevent assent to explanations that, from modernity, assimilate the crisis to the figure of a reiterated and imponderable movement. However, this analysis will focus in the potentiality of rupture and movement related to the determined that in its krisis base it brings. Through a genealogical journey dealing with the specific treatment of this notion in the medical knowledge of classical Greece, it addresses the crisis emphasizing the 'active epistemic status' enabled by krisis when it forces to effect and to risk a critical action. This anachronism will prove its productivity against the heuristic challenges requested by the perspectives of contemporary political philosophy, when it comes to reviving the critical framework of the crisis in our present time.
\end{abstract}

Keywords: Crisis and action - temporality - genealogical studies - contemporary political philosophy - presentism

\title{
Resumo
}

Os estudos filológicos clássicos se reúnem para apontar que a "crise" vem da palavra grega "krisis", cuja raiz * krr é comum a um cortejo de noções que invocam as noções de corte, de morte, de redirecionamento e liderança. O estudo deste substrato polimorfo ampliará a visão da mesma e impedirá o assentir às explicações que, da mão da modernidade, assimilam a crise à figura de um movimento reiterado e imponderável. Esta análise incidirá, na mudança, na potencialidade de ruptura e de movimento em relação ao dado que em sua base krisis traz consigo. Através de um recorrido genealógica que vai se ocupar do tratamento específico desta noção no saber médico da Grécia clássica, a crise será abordada enfatizando o "estatuto epistêmico ativo» habilitado por krisis quando obriga a efetuar e arriscar uma ação crítica. Este anacronismo provará sua produtividade frente aos desafios heurísticos solicitados pelas perspectivas da filosofia política contemporânea, na hora de reviver o marco crítico da crise em nosso tempo presente.

Palavras-chave: crise e ação - temporalidade - estudos genealógicos filosofia política contemporânea - presentismo

\section{Introducción. Crisis y tiempo presente-presentista}

A menudo pensamos la crisis como algo dado por evidente y necesario. Desde que el capitalismo incluyó este concepto como parte 
de su dinámica inevitable (Marcuse 1954) y la modernidad la hizo carne de su proyecto emancipatorio (Benjamin 1940), pareciera no haber generación que haya quedado a salvo de su experiencia, ni que se encuentre, sin más, tomada por sus altibajos, por su "plena presencia". Como si quisiera perpetuar su lógica al infinito, "la crisis" hoy ha perdido su fertilidad conceptual activa, por así decirlo: ya no es una clave heurística capaz de inteligir aquello que efectivamente ocurre en la experiencia, ni de diagnosticar lo que hace problema en nuestro mundo contemporáneo. Tampoco esta noción parece haber contribuido a impulsar, a nivel práctico, una "acción" capaz de resolver sus conflictividades, ni de trastocar o poner fin a su inercia.

La crisis, en cambio, sí se ha instalado como parte de las figuras que componen el paisaje de las discursividades que configuran nuestra actualidad. Todos podemos reconocer haber nacido en un mundo en crisis, donde no hemos cesado de oír hablar de ella a lo largo de nuestro ciclo de vida, y del que partiremos sabiendo que no se habrá hallado modo de solucionarla. La crisis, así, devino pieza inherente de la reproducción temporal requerida por las lógicas explicativas de la continuidad entre capitalismo y modernidad, cuya forma actual, caracterizada como "tardía" o "extremada", marcaría las características históricas y subjetivas de nuestro tiempo presente (Virno 2003, Lazzarato 2006).

Probablemente, una de las construcciones categoriales que mejor dan cuenta de la impotente capacidad actuante de la crisis en nuestro tiempo presente sea la elaboración de la noción de "presentismo", realizada por el filósofo e historiador contemporáneo François Hartog (2003), mediante la cual caracteriza — por la vía de la metáfora — las particularidades del régimen de historicidad ${ }^{2}$ de nuestro tiempo pre-

2 La noción de "régimen de historicidad" es el título de una de las principales obras de F. Hartog, en la que, de hecho, también desarrolla la idea de "presentismo" que estamos presentando brevemente aquí. Se trata de Régimes d'historicité. Présentisme et expériences du temps. Paris: Ed. Du Seuil, 2003. Sin embargo, esta noción ya había sido presentada por Hartog en un artículo temprano intitulado "Temps et histoire. Comment écrire l'histoire de France?", Annales Hss, novembre-décembre 1995/6: 1219-1236, en el que ya se formulaba una definición de régimen de his- 
sente. Según sus hipótesis heurísticas, que siguen la analítica paradojal ya habilitada para el trabajo de la historia por Pierre Nora (1978), las relaciones que el presente establece con los otros tiempos -el pasado y el futuro- ya no pueden evaluarse según la visión de una continuidad histórica, sino que deben ser asidas en relación al diagnóstico de "las crisis" 3 de experiencia del tiempo que evidencian. En efecto, desde esta perspectiva, no es la continuidad entre las diversas temporalidades sino sus modos de articulación los que dan cuenta del espesor subjetivo de nuestras experiencias. Así, desde esos nudos problemáticos se va configurando una suerte de orden móvil o de "régimen", modelador tanto de nuestras maneras de decir y de vivir el tiempo, como de cifrar el ejercicio de nuestra capacidad actuante en él. Desde este punto de vista, entonces, las crisis son nodales: sirven para establecer una suerte de síntoma de aquello que hace problema en el aquí y ahora a nivel experiencial, y descalzan la mera visión de linealidad temporal presente-pasado-futuro.

Para Hartog (2003), el presente, en consecuencia, habría perdido un vínculo productivo y fértil con las otras temporalidades que organizan la experiencia. Según su análisis, nuestro tiempo actual obedece al mandato de entablar un lazo continuista con el pasado, produciendo

toricidad, como "una formulación de saber de la experiencia del tiempo que, a su vez, modela nuestras maneras de decir y de vivir nuestro tiempo" (la traducción es nuestra). Hartog se muestra cercano a las formulaciones foucaultianas acerca de las "epistemes", como estratos historizados de relaciones de saber que marcan cierta configuración de una época, y al legado de la historia conceptual mediante la cual R. Kosselleck interpela los modos de vinculación entre presente, pasado y futuro. Para Hartog, la noción de"régimen de historicidad" pone el foco primeramente en los modos de articulación que van pautando las crisis entre las temporalidades que, en determinado momento, configuran un pasado, un presente y un futuro de la experiencia. Si el vínculo entre una de estas dimensiones se halla en crisis, las otras dos dimensiones se ven seguidamente afectadas. Hartog caracteriza como "desorientada" nuestra relación con el tiempo y "desquiciada" nuestra brújula histórica. La inteligibilidad del tiempo presente —el tiempo que condiciona y orienta nuestra acción-, desde sus argumentos, se muestra difusa y ya no podría adosarse a una visión clara del pasado ni a una perspectiva tangible de futuro.

3 "Las crisis", mencionadas en plural, visto que recuperan el material polimorfo de la experiencia y puesto que atañen a una triple articulación relacional entre presente, futuro y pasado. 
torpes superposiciones entre sus elementos, trocando el gesto del salto crítico, propio del anacronismo histórico, por la circular, rumiante y pasiva rememoración de sus discursividades. De este modo, se muestra incapaz de dar cuenta de sus discontinuidades concretas, de hacer pie en los conflictos reales que elaboraron sus relaciones de fuerza y encontrar allí pistas para una posibilidad actuante en el ahora. El pasado, así, en crisis de relación con el presente, ya no hace mella en él. En cuanto al futuro, tampoco parece hacer caso de las interrogaciones impuestas por su crisis en el presente. En efecto, tomado por el discurso de su crisis (y no por su fuerza práctica), no puede proyectarse como tiempo-espacio diferente, ni ofrecer una posibilidad efectiva a nivel de la experiencia que se quiera realmente crítica de lo actual en un devenir del mundo. En consecuencia, habiendo producido la unificación de estas tres temporalidades, el presente —cual Cronoshace realidad su mito y engulle los otros tiempos. Los sustrae para sí, anudando la experiencia de la temporalidad a la legitimidad de un solo tiempo —al decir de Hartog_ " presentista" (2003 134). Puesto que ha "acordado" sus parámetros de lectura a este orden discursivo, anula el carácter crítico que "sus" crisis de relación con las otras temporalidades podrían, en cambio, impulsar como práctica diagnóstica en la contingencia. Así, desde la metalógica hartogniana, el régimen de historicidad presentista actual instala "Ia" crisis del tiempo - ya no es más que una sola— como una "omnisciencia monstruosa", una instancia indefectible, que naturaliza su (in)visibilidad y la dispensa de toda posición activa otra que la de su reproducción.

Los términos de Hartog permiten posicionar un diagnóstico del presente posible: nuestro momento actual pareciera estar marcado a fuego por la dilación extendida de una vivencia siempre en presente, que no puede dar lugar a pensar y a actuar otras temporalidades posibles. Así, tomada por la lógica de la repetición de una temporalidad que, a simple vista, se asimila en un horizonte de condiciones y de expectativas amalgamado y siempre igual, la crisis parece haberse instalado en las discursividades -las de los medios dominantes, las del sentido común, pero también la de cierta tradición de la filosofía —, afianzando una suerte de - permitámonos la expresión- "estatuto epistémico inactivo" que, como mencionamos, aún si bien da cuenta de su presencia conceptual en 
los problemas del mundo contemporáneo, desconoce la lectura de su contingencia y el diagnóstico de sus posibilidades actuantes. De esta manera, la crisis aparece como una noción cerrada sobre sí misma, como una suerte de bucle temporal cuya visión a nivel discursivo promulga un pronóstico de futuro y la efectuación de un corte con las lógicas del pasado que, finalmente, en la práctica, no realiza. Frente a esta escena de circularidad enviciada (Marcuse 1954), siempre ávida de engullir toda posibilidad discursiva y experiencial que no sea la de su iterabilidad, ¿cómo reavivar la crisis de su impotencia?

Junto con Hartog, entonces, tomaremos el relevo de la filosofía política contemporánea, perspectiva crítica y paradojal que sitúa su producción teórica en el registro de las prácticas de la experiencia. Desde esos posicionamientos, Michel Foucault (1966), por ejemplo, insistía en la urgencia de dar cuenta de las relaciones que hacen problema en nuestra actualidad —las crisis—, y siguen sin ser nombradas. Para ello es preciso entonces que la filosofía trabaje sobre las pistas de un diagnóstico crítico del presente (Foucault 1984, 1984b) ${ }^{4}$, dando cuenta de los problemas que ha preferido invisibilizar, porque aún no puede (o desea) inteligir.

4 M. Foucault posiciona a la tarea filosófica frente a un diagnóstico crítico del presente en sus últimos cursos (1983, 1984), escritos y entrevistas (1984b). Realizando un desplazamiento respecto de todo entendimiento que ligue "ontología" a una verdad fija, Foucault concibe en cambio su trabajo filosófico como tarea dinámica y crítica, que ha de poder situar la pregunta kantiana por el "quiénes somos" en los términos que actualmente cifran las condiciones para una ontología del presente o una ontología histórica de nosotros mismos. Este trabajo de reconstitución de nuestros "modos de ser", de nuestro ethos actual, se articula en tres dominios de trabajo: la ontología histórica de nosotros mismos será inquietada en su relación con la verdad (las cuales permiten constituirnos en sujetos de conocimiento), en nuestras relaciones respecto del campo del poder (las cuales nos constituyen como sujetos capaces de actuar sobre los otros) y en nuestra relación ético-moral (que nos constituye en sujetos éticos). Cada uno de estos dominios, como vemos, corresponde a uno de los períodos que suelen ser distinguidos en el trabajo de Foucault: arqueológico, genealógico y ético. Mediante la articulación problemática de estas dimensiones, Foucault aborda un análisis de la constitución histórica de nuestra subjetividad, para diagnosticar y realizar una crítica práctica de las condiciones de posibilidad que configuran el ethos de nuestro presente, y para situar allí una crítica práctica (1984), formas concretas de resistencia y modos de franquear los límites de nuestro propio tiempo. 
Al llamado de esta urgencia, sumamos modestamente las siguientes preguntas, que pretenden arquitecturar el núcleo problemático de este artículo:

¿Puede, la crisis, devenir una de las nociones activas de esta tarea crítica? ¿Es posible resignificar la crisis a partir lo de que hoy hace crisis en la práctica misma? Si es cierto - tal como nos enseñan las perspectivas de la filosofía política contemporánea- que a través de ella hemos de cifrar las claves del diagnóstico crítico de nuestro presente, y tomar distancia para poder actuar en él de otra manera a como es ya sabido, contribuyendo a bifurcar el círculo vicioso de la iterabilidad de la crisis, ¿qué conceptualizaciones habremos de hacer de esta noción? ¿Qué perspectivas podrían sostener la apertura epistémica capaz de inteligir lo que hace y seguirá haciendo crisis en una experiencia, que, en cada acontecer, requiere ser situada en sus particularidades histórico-temporales? ¿Cómo desdoblar el vínculo que hoy anuda sin más crisis y presentismo? ¿Qué relaciones analíticas podrán, efectivamente volverla una clave heurística fértil para interpelar — para producir un écart_- en nuestra comprensión de la actualidad?

Ciertamente, será preciso diversificar los abordajes de la crisis y puntualizar los matices y diferencias que hacen a las especificidades de estos enfoques que aquí nos permitimos, muy someramente, introducir a la manera de un conjunto. Empero, en función de recuperar un entendimiento más vasto de las posibilidades heurísticas de esta noción, realizaremos un estudio genealógico de sus conceptualizaciones, atendiendo particularmente al tratamiento que la idea de "crisis" revestía en el contexto de la Grecia arcaica y clásica. Intentaremos recuperar los elementos capaces de poner en valor, específicamente, el estatuto epistémico activo que reviste su uso, ligado a la cuestión de la "acción crítica" en los desarrollos de la Medicina Hipocrática. Así, adentrándonos en las piezas del registro histórico, llevados por una cuestión que hace problema en nuestro presente ${ }^{5}$ - tal como lo

5 El trabajo de —en-la historia de la genealogía se opone a la búsqueda del "origen" (Foucault 1979), invitando en cambio a localizar la singularidad de los acontecimientos en función de sus relaciones de emergencia — procedencia—. La genealogía deviene 
requiere el gesto genealógico (Foucault 1971), caracterizado por el tratamiento a contrapelo de la historia por parte de las perspectivas de la filosofía política contemporánea-, efectuaremos un salto en el tiempo, anacronismo fértil cuya toma de distancia respecto del tiempo actual nos permitirá habilitar una comprensión más amplia de las paradojas y complejidades de nuestro presente.

\section{Etimología y semántica de krisis}

Etimológicamente, crisis proviene del vocablo griego krisis, cuya raíz "*krr" filológicamente remite a la idea de una acción que puede venir a nombrar un tiempo-espacio de corte, de muerte, de bifurcación, de nuevo comandamiento; es una acción que implica una toma de una decisión que parte aguas. Este mandato etimológico emparenta krisis a la idea de krino (juicio, separación), krinein (reparto, distribución), krasis (mezcla), kratos (poder, jefatura), kuno (decisión).

Ciertamente, tomada por el eco de este cortejo semántico, krisis, en el contexto arcaico que hizo emerger esta noción, hereda una filiación que se traduce como capacidad de intelección de la multiformidad de elementos que componen su contingencia, con vistas a actuar en él. Su estatuto es variable y se encuentra siempre ligado al carácter mezclado de las circunstancias que generan su aparición. Por ello krisis tiene la facultad de poder remitir y vincular varias situaciones disímiles a la vez, yuxtaponiendo órdenes discursivos y saberes diversos que, contrariamente, desde otro tipo de registro analítico estarían cantonados según sus diferencias. Krisis, así, desde un inicio, precisa de las krasis de las circunstancias concretas, de su entremezclado de

un método de lectura de la discontinuidad de prácticas que van haciendo la historia, para Foucault, y una pieza para desarmar toda pretensión unificadora de relatos. También es una herramienta que le permite realizar una arqueología de su propio tiempo, puesto que por la vía de los anacronismos sitúa en la profundidad histórica un punto problematizador de lo actual, capaz de hacer décalage sobre los modos que hemos dado por evidentes, puesto que varias de sus interrogaciones siguen marcando cuestiones que son problemáticas en nuestro presente. á su hálito apolíneo y se ligadafrimiento que hablar de crisis implicansado $y / o$ dado por evidente.. $r$ binarizado. 
prácticas, saberes, afectos, conflictos y pasiones. Es en esta materialidad heterogénea y compuesta donde krisis emerge, para actuar en un orden dado de posibilidades que, en cada situación, convoque su decisividad crítica.

En consecuencia, krisis, etimológicamente, no ostenta un saber desligado de su ejercicio. No se erige como mandato ni opera su reproducción discursiva por fuera de las prácticas que la señalan. Su capacidad heurística es tal que su lectura puede ser referida a una materialidad concreta aquí y allá, en contextos diversos y siempre circunstanciados, y separar (krino) las lógicas unificadas que impiden pensar otras posibilidades actuantes y/o juzgar un nuevo re-parto (krinein) respecto de las distribuciones vigentes. El punto en común, empero, radica en que, sea el caso que sea, krisis viene siempre a marcar una posibilidad de interrupción respecto del orden ya dado.

En este sentido, es importante subrayar el énfasis que krisis porta desde su filología y que acentúa la idea de corte y de muerte ligada al radical *krr. Esta disposición le exige hacer honor a su capacidad actuante: krisis, en la configuración que le dio emergencia, tal como mencionamos, solicita una acción bifurcativa, una toma de decisión que de corte a las mezclas circunstanciadas tal como vienen siendo legitimadas. Este re-parto de aguas apunta a solucionar - o al menos, dar alguna respuesta - a aquello que en la práctica hace problema y ha quedado superpuesto, amalgamado o invisibilizado en la mezcla (krasis) y en las distribuciones (krinein) vigentes, y convoca la necesidad de su emergencia.

\section{La crisis en el saber médico}

Tal vez sea interesante recabar en una de las disciplinas que ha hecho de la crisis un punto nodal de su ejercicio epistémico y técnico: el saber médico. En este sentido, y prosiguiendo el recorrido genealógico, es interesante tener en cuenta las particularidades que asume la elaboración de saberes en el contexto de unificación de las technai de la Grecia del siglo V a. C., puesto que es el momento en donde la 
naciente Medicina Hipocrática jugará un rol fundamental y marcará una posición paradigmática inédita ${ }^{6}$.

Es necesario recordar que en el siglo $\mathrm{V}$ a. C., Grecia está surcada por la crisis de composición que impone a la multiplicidad de las cosas el "modelado" cósmico del mundo según la lógica relacional de la physis. Este concepto, heredado de la filosofía jónica de la naturaleza, otrora aplicado en función de una comprensión del kosmos en su conjunto, en la era de la techné, en cambio, es transferido al terreno del hombre, quien, tal como lo describió Demócrito (460-370 a. C.) "...es como el mundo en pequeño"7. De esta manera, el hombre se concibe por analogía a la naturaleza como una unidad de conjunto, organizada, sistematizable. Su estudio y conocimiento habrá de permitir, en consecuencia, garantizar el tratamiento y la conservación de su equilibrio (que, como veremos, es el horizonte que trazan los ideales apolíneos de la Grecia clásica).

Las pertinencias de las diversas epistemes se hallan entonces así compelidas a organizar sus saberes arcaicos a la manera de artes racionales, capaces de sistematizar el registro de lo empírico y definir las reglas de una técnica. Se esperaba que ésta fuese plausible de abordar, analizar y prever el tratamiento de cada situación. Así, las diversas technai se configuraban según criterios matemáticos que regían la necesidad de cotejar en cada caso criterios de medida, número y exactitud ${ }^{8}$. Ahora

6 Probablemente solo igualada como gesto disruptivo por la práctica de los Sofistas, quienes hacían de la krisis una oportunidad actuante del discurso sobre el otro. Tal como recordaba Gorgias, el ser puede ser o no ser, y en este registro ambivalente y móvil se dirimía una posibilidad decisiva siempre bifurcativa del orden de saberes en cuestión (Cassin 2004).

7 Demócrito. "Máximas", en Fragmentos Presocráticos: de Tales a Demócrito. Buenos Aires: Alianza, 2008.

8 La noción "akribéia" designa un horizonte de búsqueda en la physis (naturaleza) que, de la mano de las technai en el siglo $V$ a. $C$., solicita un orden que ha de recurrir siempre a la misma fórmula "técnica": será preciso respetar, ante todo, el seguimiento de una medida peculiar, con pretensiones de precisión, que no será de ahora en más sino la resultante de un cálculo entre el "número" y el "peso". Estos tres términos (medida, número y peso) son indisociables y su articulación es la única garantía de "claridad" y de "exactitud", frente a una producción de saberes cada vez más creciente en la maraña común de la polis clásica. Ver al respecto el estudio de F. Heinimann (1975 55), consagrado a la tríada "medida, número, peso". 
bien, ¿cómo dar cuenta de estos requerimientos en la multiplicidad mezclada de las circunstancias? ¿De qué manera podrían articularse las exigencias de estos criterios, de modo de no arrancar a krisis la potencialidad semántica y activa que comporta su uso, de modo de no unificar su movilidad a una techné siempre solícita de mostrarse mensurable, calculable y exacta?

De un modo ciertamente revelador y sincero, la Medicina Hipocrática fue el primer ámbito de saber que se animó a confesar hallarse frente a una imposibilidad teórico-práctica a la hora de arribar a estos ideales. Efectivamente, en el ámbito del saber médico, medida, número y exactitud operaban como criterios organizativos, pero no podían garantizar su funcionamiento como factores de validación epistémica. Es tanta la complejidad de factores intervinientes en las causas de las enfermedades, en sus procesos de evolución, en sus métodos de cura, que la cuestión de una acción concebida como akribeia, la exactitud, en el ámbito médico no podría ser mantenida más que como una suerte de expectativa, de horizonte ideal.

Más humildemente, y como lo explicita Hipócrates en la letra de uno de los Tratados denominados "Teóricos" y conocido como Antigua Medicina, su saber habrá que contentarse, sin más, tan sólo con "apuntar a una especie de medida", confesando que, en este ámbito complejo, "raramente es posible tener la exactitud absoluta":

Si la cosa fuese tan simple como pareciera indicarse, si fuese cierto que el alimento demasiado fuerte fuese siempre una incomodidad, el alimento más débil siempre una ventaja, tanto para el enfermo como para el hombre saludable, el asunto sería fácil a reglar: ya que bastaría con crear un ancho margen de seguridad respecto del alimento más débil. (...) las cosas son mucho más complejas y requieren un método exacto: es preciso apuntar a una especie de medida. Sin embargo, en cuestión de medidas no podríamos hallar nombre ni peso como referencia para un conocimiento exacto que no sea el que resiente el cuerpo del enfermo: trabajo duro es el de adquirir una ciencia lo suficientemente 
precisa como para no cometer errores ligeros, ni en un sentido ni en el otro; en cuanto a mí, no dejaría de cubrir de elogios al médico que comete errores ligeros ya que raramente es posible tener la exactitud absoluta?.

En efecto, la vastedad de tratados, estudios y escritos que compone el Corpus Hipocrático (420 y 350 a. C.) da cuenta de esta diversidad: saberes teóricos se combinan con saberes prácticos, análisis de anatomía humana y animal, enfermedades y afecciones, humores, epidemias, dietas, enfermedades de la mujer, articulaciones, fracturas, descripciones de los diversos "lugares", y su influencia en los aires y las aguas, etc.; también, exámenes que versan sobre el punto de vista del médico, entre otros.

Como si el Corpus no pudiese demostrar más que el gesto de una condición humana frente al infinito, la heterogeneidad de estos capítulos muestra la avidez de un campo de saber que sólo sabe que siempre quedará incompleto. Ciertamente, en materia de saber médico, las causas y factores a identificar resultan de elementos mezclados y tan dispares entre sí que es imposible siquiera soñar con anticiparlas completamente. La crisis aquí, tal como veremos, surge de la puesta en visibilidad de una situación contingente: la enfermedad, que, heredera de un imaginario arcaico, se explica como causa de un desequilibrio del cuerpo. Gracias a la intervención del saber del médico este desequilibrio intentará reequilibrarse, aunque sabiendo que nunca ha de quedar exento de su carácter inestable.

\section{Equilibrio/desequilibrio como pares no dicotomizables}

Es interesante detenerse a atender un poco más pacientemente esta cuestión de los equilibrios y desequilibrios del cuerpo, ya que, de un modo ciertamente complejo y lejos de la figuración numérica y/o cuan-

9 La traducción y el resaltado son nuestros. Hipócrates, Antigua Medicina, Littré: I, 1839588 (Trédé 1992 164). 
tificable de una balanza, en materia de salud, el equilibrio es frágil y, una vez desequilibrado - - contra toda tentación continuista—, nunca retorna al mismo punto en el que se encontraba antes (tampoco este movimiento implica -modernamente- necesariamente una pérdida, a veces el retorno es débil, otras veces, se retorna con más fuerza).

¿Cómo se compone entonces esta configuración siempre bifurcada de la dinámica equilibrio/desequilibrio como objeto de las prácticas de saber de la Medicina Hipocrática?

Primeramente, es preciso tener en cuenta, tal como anticipamos, que "la salud" para la medicina hipocrática es consecuencia de un equilibrio (symmetria) que resulta de la mezcla adecuada de los elementos constitutivos del hombre. Esta idea, que proviene del imaginario arcaico de los cuatro humores ${ }^{10}$, habría sido formulada por primera vez por Alcmeón de Crotona, quien definía a la salud a la manera de una isonomia o isomoira, esto es, mediante una dinámica temporal capaz de ir manteniendo las proporciones (estamos en el mundo de krino) entre los distintos elementos del organismo, puesto que así aparecen equilibrados también en el conjunto de la naturaleza.

Sin embargo, tomando distancia de las afirmaciones "presocráticas" -que veían por ejemplo en el "calor" un principio natural causante de toda salud, así como de toda enfermedad—, la Medicina Hipocrática pretende en cambio abarcar un mayor espectro de causalidades, entendiendo que el accionar de las mismas nunca será aislado, sino relacional. Como claves de una dinámica más compleja, entonces, lo salado y lo amargo, lo dulce y lo ácido, lo áspero y lo suave, etc., que antes balizaban los movimientos de opuestos complementarios, ligados a los diversos humores del cuerpo, ahora forman parte de la gran diversidad de factores a tener en cuenta a la hora de "juzgar"

10 Para la 'teoría de los humores' las cualidades que caracterizan los humores humanos son ordenados en cuatro grupos $y$, destacando sus interrelaciones, se sostiene que funcionan conforme a 'pares de opuestos': sangre y bilis negra, flema y bilis amarilla. Correlativamente, se asocian a cada uno de los elementos de la physis, que también son cuatro: aire, tierra, agua y fuego, y configuran el imaginario arcaico de causas y efectos de las enfermedades. 
(krino) la enfermedad, en el momento de identificar su krisis - tal como veremos más adelante. En efecto, la enfermedad constituye una "agresión"11 contra el equilibrio; una especie de amenaza a la isomoira, cuyas alteraciones —que son objeto de un registro casi "etnográfico" en el primer libro de los volúmenes titulados "Epidemias" — dan prueba del espacio infinito de las circunstancias. Ciertamente, los factores de desequilibrio son innumerables, e incontable también es la producción de sus efectos, debido a la gran diversidad de individuos, hábitos alimenticios, modos de vida, factores climáticos, enfoques terapéuticos, etc. que pueden estar presentes. Siguiendo esta lógica, para este saber el equilibrio saludable siempre resultará de una "mezcla" (krasis) de elementos. Los repartos (krinein) saludables/no saludables entre estos elementos, siempre situados en una circunstancialidad determinada, son los que permitirán interpretar una definición de la "enfermedad" que adviene como un desequilibrio causado por la supremacía de uno de esos elementos sobre los otros (Mac Kinney 1964). Krisis, tal como veremos en lo que sigue, es el punto álgido, akmé, que desencadena este reparto de equilibrio/desequilibrio al servicio de la salud y la enfermedad. Su emergencia ocurre en un espacio-tiempo complejo, donde es preciso reposicionar cada vez los términos de su equilibrio, siempre condicionado por la dinámica relacional del contexto, y actuando de un modo siempre diferido respecto del estado anterior.

En este sentido, la medicina hipocrática asume que, si bien los procesos de equilibrio y desequilibrio remitiendo a la salud o a la enfermedad no podrían predestinar su devenir ni retornar a su punto de destino, sí radica en la techné médica el esfuerzo por sistematizar lo más exhaustivamente posible todo conocimiento incidente en estos

11 Es interesante esta consideración de la pérdida de equilibrio conducente a una enfermedad, como una "agresión" contra el cuerpo y/o el organismo, puesto que ha nutrido no pocos enfoques contemporáneos, como ser las escrituras acerca de inmunitas por parte del filósofo italiano Roberto Esposito (2005), por ejemplo. Para ampliar las referencias arcaicas y clásicas acerca de la "enfermedad" como agresión, es muy revelador el estudio presentado por J. Jouanna «Médecine et protection. Essai sur une archéologie philologique des formes de pensée», en Formes de pensée dans la Collection Hippocratique, Actes du colloque de Lausanne, Genève, 1983:21 y ss. (Trédé 1992 151). 
procesos, de manera tal que puedan ser correctamente abordados e incluso, algunas veces, tal como veremos más adelante respecto del Pronóstico, "previstos". Tal es la pretensión teórica de un saber médico que debe ir sistematizando los datos multiformes que va registrando respecto de la salud y la enfermedad, a través de una dinámica de equilibrio/desequilibrio distinta cada vez, y que tiene lugar a lo largo del tiempo. Así, incrustado en la materialidad de las circunstancias, para esta producción de saber "...todo resultado positivo dependía de la observación exacta de los hechos concretos y lo que en ella se ventilaba era la vida humana" (Jaeger 1957 801).

De esta manera, teniendo como centro la vida humana, la productividad y el alcance de las contribuciones del saber médico no podrían encallar en una reflexión acerca de lo que el hombre "es" en términos de naturaleza. Al contrario, tal como se plantean los objetivos del Corpus Hipocrático, el foco de esta ampliación de la mirada está aquí en atender a "lo que [el hombre] es en relación con lo que come y bebe y a cómo vive y a los efectos que todo esto produce en él"12 (Hipócrates 20). Atender a lo que "el hombre es en relación con"... Solo una perspectiva relacional que considere articuladamente el registro de la particularidad de sus usos podrá sostener, tan cercanamente como pueda, la cercanía de la akribeia. Solo una perspectiva dialógica podrá sostener la sensibilidad y la escucha que supone esta práctica siempre recompuesta de saber.

\section{Escuchar, sentir, dialogar la krisis}

Si fuese posible encontrar para cada constitución individual una proporción exacta de los alimentos $y$ de los ejercicios sin exceso ni defecto, habríamos encontrado entonces muy exactamente la salud para todo el mundo.

(Hipócrates 470)

12 Nuestra traducción. 
De un modo sin duda más humano y falible, los hipocráticos sabían que, frente a la enfermedad, únicamente era posible acercarse a una escucha de los síntomas, a la comprensión dialógica de su percepción. Esta capacidad de apertura subjetiva en medio de las circunstancias, con vistas a ampliar una posibilidad de intelección, era la única vía capaz de emprender la identificación de sus causas. Solo así podrían éstas inscribirse luego en un saber epistémico y devenir plausibles de componer un pronóstico de las acciones factibles a emprender para su cura.

La práctica médica no viene entonces únicamente asegurada por criterios racionales. Precisa dar cuenta de la vida humana en tantas dimensiones como sea posible $y$, al respecto, ciertamente uno de los aportes más interesantes de la antigua medicina es la redefinición del arcaico y clásico metrón ${ }^{13}$ : como un ejercicio práctico que viene siempre ligado a la tarea de "percibir el cuerpo".

La investigadora Monique Trédé, de este modo también pone en valor este desplazamiento:

Es mérito de la medicina griega haber intentado definir un "metrón" capaz de permitir, cada vez, una finalidad terapéutica precisa, adaptándose a la diversidad de temperamentos y remedios. Entre la unicidad — sin cesar variable-, y la totalidad, que solo permite una certeza definitiva, la medicina griega define su vía, la de la pluralidad, en un mundo donde todo se concibe de un modo relacional (Trédé 1992 168) ${ }^{14}$.

El lento trabajo de escucha de la pluralidad relacional que impone el vínculo del cuerpo con el contexto, entonces, hace del metrón una llave heurística paciente. Debe atender a ir vinculando las distintas

\footnotetext{
13 Recordemos que en el mundo arcaico "Metrón" era un vocablo portador de la estirpe apolínea del orden, rigiendo sobre las medidas justas y las proporciones equilibradas entre los hombres en términos generales. En el pensamiento clásico continuará su hálito apolíneo y se ligará al imaginario virtuoso de los criterios de prudencia (entre el exceso y el defecto, tal como nos recuerda Aristóteles), en función de sostener las summetrias (medidas, proporciones, equilibrios) requeridas por la práctica política, ética, estética, médica, etc.

14 La traducción es propia.
} 
percepciones y los diversos tiempos que componen la práctica de la aisthesis toû somatòs, la "percepción del cuerpo". No es nuestra intención realizar una descripción exhaustiva de los pormenores que hacen al debate filológico sobre la traducción de esta expresión — que oscilan entre una interpretación ligada al régimen de alimentos y otra a la escucha de los síntomas en el relato dirigido al médico (Trédé 167)—, pero sí nos interesa recuperar el doble sentido que comporta aisthesis: puesto que la formulación "percibir el cuerpo" se refiere tanto a la cuestión del régimen y al estudio de los efectos de su administración minuciosamente dosificada para lograr la cura del enfermo, como a las sensaciones que el paciente percibe en su cuerpo cuando consulta al médico. Esta percepción relacional, así, tiene como centro un diálogo médico/paciente y va conformando un saber combinado, a la vez sensorial y técnico. De esta manera, la práctica médica recaba su propia palabra a través de una articulación con un saber siempre parcial circunstanciado, y va conformando su propio saber habilitando una escucha que requiere la disponibilidad de apertura propia de una relación dialógica: es preciso escuchar, sentir, inteligir, el testimonio del paciente. Asir su dolor, su preocupación. Situar su problema. Entre uno y otro, médico y paciente así asumen un riesgo: el que implica la tarea de "traducir" un mundo subjetivo, sintiente, para desplazarlo al orden del pronóstico. Es el médico quien debe incorporar este saber: inscribir epistémicamente las vivencias que le han sido relatadas, las sensaciones, las recurrencias, las excepciones del paciente. En este diálogo, en el que el metrón está al servicio de una heurística de la contingencia, el médico puede validar la descripción de las sensaciones percibidas por el enfermo, porque su relato es articulado, probado e integrado a una tipología — eidos - de las aisthesis, que luego formulará un pronóstico. Saber y percepción se articulan entonces en la búsqueda de ese metrón como medida ajustada a lo que va haciendo krisis en cada situación. Una suerte de dominio intuitivo se incorpora entonces como parte del acto de conocer.

De un modo revelador, la articulación entre testimonio e interpretación, entre el relato del enfermo y el del saber hacer del médico, compone una especie de lenguaje "a dos voces" con el que se va armando la definición de los "puntos críticos" de la crisis en cuestión. 
Este diálogo polifónico debe arribar a detectar cuáles son los "signos críticos" (epikaira semeia): posición del enfermo en su cama, chirrido de dientes, delirio, sudores, frío o calor en las extremidades del cuerpo, calidad del sueño, deposiciones, orinas, vómitos, escupidas, etc., que, a simple vista, nada valen por sí mismos, sino que adquieren su relevancia problemática cuando son puestos en relación. De este modo, el arte de prever tanto la cura como la reincidencia, la cronicidad o el deceso de una persona, se basa en la conjunción de todos estos datos y de todos estos momentos. Solo siguiendo este procedimiento podrán determinarse los momentos decisivos de la enfermedad, los tiempos cruciales para la acción terapéutica.

Así, tal como veremos en lo que sigue, el médico, frente a los signos críticos que percibe en el enfermo, solo puede "pronosticar", es decir, componer un eidos — una elaboración de "tipos", "disposiciones", "formas" - de modo de poder comenzar a planificar las curaciones posibles. Este saber le permite actuar, ciertamente, aunque no anticipar completamente un resultado: si un cuerpo enfermo representa una pérdida de equilibrio, el médico, al igual que el navegante homérico, debe pilotear las pruebas más difíciles en el medio de un universo móvil y cambiante, para hacer frente al desafío de restablecer el equilibro perdido, sabiendo que éste nunca volverá a ser el mismo. Así, definiendo el cada vez de su metrón, el médico mensura los conocimientos más ajustados a las particularidades de su caso, y los dispone a la dinámica del devenir. En efecto, la discriminación de los factores influyentes en cada coyuntura implicará de ahora en más la consideración ineludible de una dimensión temporal que no podría ser leída de un modo continuista, ya que, transida por el desequilibrio de krisis, en su seno habilita una discontinuidad que podría ser ruptura.

\section{La temporalidad no transicional del pronóstico}

La cartografía de esta problemática es inmensa y a los fines de los argumentos principales ligados a la temporalidad en este artículo, examinaremos finalmente las tesis centrales que componen los llamados "Tratados Clínicos" del Corpus hipocrático. Especialmente, nos deten- 
dremos en los escritos intitulados "Sobre las crisis" y "Sobre los días críticos y Pronóstico", para dar cuenta de la temporalidad específica, cualitativa y actuante en la que se inscribe la crisis en este contexto.

En este sentido, es necesario tener en cuenta, tal como lo hemos desarrollado, que en la configuración clásica que estamos analizando aquí, las perturbaciones que causan el desequilibrio de un cuerpo y provocan una enfermedad buscarán ser aprehendidas como parte de "procesos" que han de ser tratados teniendo en cuenta su discontinuo desenvolvimiento temporal. Dijimos: la crisis es marca de un desequilibrio que se sabe nunca completamente reequilibrable, y esta dinámica paradojal que marca su accionar resulta ciertamente interesante para las preguntas que elaboran las hipótesis de trabajo de este artículo.

Tal como lo explicitan los libros V y VII de las Epidemias ${ }^{15}$, estos procesos, lejos de ser unilineales o monocordes, se compondrían de una mezcla (krasis) de factores, causas y tiempos desiguales. Mediante este registro, entonces, es que se habilita la elaboración de la suerte de eidos temporal que supone el Pronóstico, es decir, una tipología de "fases" o "prognosis" sistematizadora del devenir de las enfermedades:

Primeramente, el momento del pepasmos o pepsis: el tiempo de "cocción" de los elementos en el cuerpo que pueden ser eliminados o transformados en "depósitos" que lleven luego a una enfermedad.

Segundo, el momento de la apostasis: el proceso de "depósito" que implica la fijación en algún punto del cuerpo de aquello que no ha podido ser eliminado.

Tercero y decisivo, la crisis o momento donde se juzga la enfermedad y la administración del pharmakon —droga, pócima-, con pleno riesgo de producir tanto la cura o el envenenamiento del enfermo.

15 Esta lectura está basada en la interpretación erudita de estos textos por parte del especialista F. Robert (1976 257, 270). 
Cuarto, el tiempo de la cura o la hipostrofe o reincidencia, que se produce según los efectos insondables ocurridos en el momento de la acción crítica.

Es interesante advertir, frente a esta sistematización de la sucesión, y desalentando toda interpretación continuista, que no por tratarse de un "proceso" esta temporalidad obedece necesariamente a un modelo transicional. Tampoco la temporalidad de estos momentos podría concebirse desasida de su cualidad o desde un registro que no dé cuenta de la singularidad específica que va haciendo a la circunscripción de "fases" que supone. Al contrario, asido desde la coyuntura de sus mezclas (krasis), el tiempo sigue siendo aquí una dimensión circunstanciada, que en cada situación ha de articular al menos tres instancias ineludibles: "...el origen de la enfermedad, su punto culminante, y la hora en la que la enfermedad es 'juzgada'" (Trédé 179) ${ }^{16}$.

Particularmente, krisis, tal como podemos apreciar aquí, ocupa el espacio-tiempo de un "momento" que es siempre un pasaje inestable. Es el "momento crítico" de la tercera etapa de la prognosis, la instancia de "juicio" -donde, por la vía de la administración ambivalente de los pharmakon ${ }^{17}$, se decidirá el rumbo fasto o nefasto del curso de una enfermedad y, por lo tanto, la salud del paciente. Es interesante reparar, en este sentido, tal como nos muestra el registro perceptivo y dialógico de sus signos, que la crisis tiende a producirse siempre en "días críticos" - tal como, según hemos visto, lo establece la modulación de etapas del pronóstico ${ }^{18}$ - . La observación minuciosa de los

16 Traducción propia.

17 Pharmakon es el nombre que reciben, en la Grecia clásica, las pócimas y/o drogas dotadas de un poder siempre ambivalente, incapaces de conjurar su efecto, ya que se mostraban, según el objeto y según las circunstancias, tanto capaces de curar como de envenenar al paciente.

18 En su escrito intitulado "Pronóstico", Hipócrates describe las fases de las enfermedades agudas, asociando a su pronóstico siempre el cálculo de un "número": "La misma cantidad de días que conducen a la cura o a la muerte de los enfermos regula las crisis de las fiebres. Las más benignas (...) se terminan en cuatro días o antes; las más malignas (...) matan en cuatro horas o antes. Tal es el límite de su primer período. El segundo período llega al séptimo día; el tercero al undécimo; el cuarto al décimo cuarto; el quinto al décimo séptimo; el sexto al vigésimo. Así los períodos de 
ciclos de cada enfermedad y la distinción de sus periodos sustenta así la edificación de otro eidos: una suerte de tipología de los momentos claves para la toma de una "decisión".

Así, tal como lo recuerda el Pronóstico:

Hay que aprender a reconocer con exactitud la constitución de cada estación y de cada enfermedad, distinguiendo (...) qué enfermedad es larga y mortal, cuál es aguda y sin peligro. Partiendo de allí, estamos en estado de observar el orden de los días críticos y extraer los elementos del pronóstico. Cuando sabemos estas cosas, sabemos también a qué enfermo, en qué tiempo y de qué manera es preciso alimentarlo"19.

En consecuencia, la importancia de estos "días críticos" radica en el peculiar lapso temporal que permite inteligir y se aboca a estudiar, visto que es donde tendrán lugar las principales modificaciones clínicas. Así, el "momento crítico", álgido (akmê), donde se juzga la enfermedad, produce la reunión entre la noción de "krisis" y el "krinein" (krino) de su par etimológico, puesto que la crisis aquí implica un pivote y/o corte que redistribuye las posibilidades del tiempo del enfermo. Tal como veremos a continuación, esta ocurrencia tiene lugar en un momento

las enfermedades más agudas van de cuatro en cuatro días hasta el vigésimo. Pero nada de todo esto puede ser calculado rigurosamente a partir de días enteros, ya que ni el año, ni el mes se cuentan por días enteros" (Hipócrates 20) (traducción nuestra). Esta periodización de "días críticos", ordenados en triadas o tétradas, tiene una larga historia en el pensamiento griego. El clásico estudio filológico de Roscher (1906) analiza esta periodización del tiempo buscando su origen en el "principio septenario" propio del pensamiento griego. Para el autor, la utilización de dicho principio en el seno de la práctica médica de los siglos $V$ y IV a. C., debe ser rastreada en su doble origen: por un lado, es heredero de las más antiguas creencias religiosas y populares sobre el funcionamiento de los planetas — especialmente, respecto de la luna — que organizan los tiempos del calendario y, más específicamente, la regulación de la porción de tiempo entendida como "hebdomadario"; el otro origen se reconoce en el legado pitagórico, cuya escuela concebía lo que se ha dado en conocer como una suerte de "mística de los números", concediendo virtudes extraordinarias a ciertos números por sobre otros. La crisis tendrá aquí un número particular (3 o 7), cuya cualidad impar le permite pivotear sobre un equilibrio que no puede ser binarizado.

19 Traducción propia. 
que tiene poco tiempo y allí ha de arriesgarse, empero, en una acción decisiva, la administración siempre ambivalente del pharmakon. El enfermo puede tanto sanar como empeorar, y aun si este destino no está asegurado la crisis es señal de que es preciso, con urgencia, actuar.

\section{Actuar en un momento que tiene poco tiempo}

Reclamando actuar en ese momento crítico, la crisis produce una apertura del tiempo escindiendo su pronóstico de una temporalidad de la transición. Este tiempo aprehendido, apropiado en el pronóstico, tal como analizamos, es siempre diferente, ya que se encuentra cualitativamente ligado a la experiencia. La antigua lengua griega reserva un nombre para el tiempo actuante asido en su cualidad: "kairós", noción cuya puesta en valor nos permitirá finalizar la instancia del presente análisis.

"El tiempo es aquello en lo que hay kairos y kairos es aquello en lo que hay poco tiempo", advertían los Preceptos (Hipócrates 250). Así se nombra al momento, con poco tiempo, de la fase "crítica" de la prognosis. Este punto de krisis le exige al tiempo erguirse con una cualidad distinta a la que ya traía y, mediante una acción decisiva, bifurcarse de la temporalidad transicional que podría incitar la lectura de un pronóstico. Ahora bien, ¿cuál es este tiempo específico que hace crisis y puede ser valorado en su cualidad, que aun siendo breve puede críticamente desdoblar el orden de posibilidades en vigor?

Kairós, esta noción arcaica, heredera de las summetrias, requeridas de los espacios justos y equivalentes de los tejidos apolíneos en la tierra ${ }^{20}$, pertenece, etimológicamente, a la misma familia que krisis, krasis y krinein, y hereda la fuerza de corte y la potencia de muerte que habita en su radical *krr. Tal como testimonia la llíada, kairós indica el punto

20 Kairos o, más tempranamente, su forma adjetiva kaïrios, es el nombre que viene a marcar las distancias justas para el entreveramiento de las lanas en el telar (Gallet, Onians), metáfora textil que será capital para el posterior tejido político de la polis, notablemente en las obras de Platón y Aristóteles. 
defectuoso de la juntura de la armadura o de la osamenta del cráneo de un caballo de guerra; es el nombre que viene a marcar las fisuras espaciales para la irrupción de un tiempo fatal ${ }^{21}$. Según cuenta el mito, este espíritu alado y fugaz, hijo de Zeus y de Tijé, artífice de la creación de oportunidades cualitativas del tiempo en el espesor severo del tiempo cuantificable de Cronos, es el nombre de las oportunidades aprovechadas y de las ocasiones perdidas.

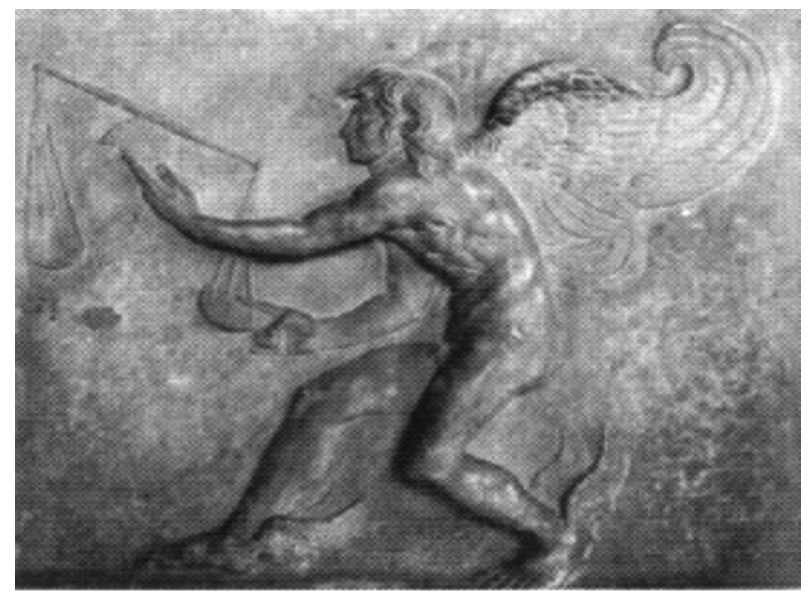

Personificación de Kairós esculpida por Lisippo para Alejandro Magno, en Pe-

Ila. Siglo II a. C., Museo de Antichità di Torino.

Tal como lo figura su imagen: es joven e intrépido, tiene alas en los pies que le permiten sobrevolar siempre cerca del suelo y no permanecer nunca en el mismo sitio. Es calvo, tal como resuena el refrán —"a la oportunidad la pintan calva" -, por lo que no hay que dejarlo pasar,

21 En el contexto de su uso clásico, tomado por la crisis que surca las epistemes del siglo $V$, kairós convocaba un registro de la multiplicidad y marcaba tanto las tensiones de las paradojas del mundo como la imposibilidad humana de pretender estabilizarlo: es, en la obra de Platón, el punto, el akmé que viene a operar de "agregado" para el tejido incomponible de la polis, es el punto de reunión imposible entre ideas y reminiscencias, es el momento crítico del parresiasta - tal como cuenta en su Carta $\mathrm{VII}$ - en el que se encuentra sin amigos y sin oportunidades, arriesgando su palabra y su vida interpelando al gobierno de lon; luego será la alerta trágica constante por una práctica de prudencia en Aristóteles, la oportunidad de un actuar pharmakológico del lenguaje, en la boca de los sofistas. 
ya que no es posible repetirlo, tampoco retenerlo. Este semi-dios tiene en una mano una navaja con la que corta el tiempo transicional y en la otra una balanza que está siempre desbalanceada —o, al menos, así aparece a nuestros ojos domesticados en la lógica de la estabilidad, puesto que los términos dados para el equilibrio no se corresponden con lo que precisa, cada vez, el juicio de su particularidad-.

En este sentido, kairós, asido por la crisis central al momento crítico hipocrático, implica siempre una toma de decisión, una acción que produzca un vuelco en el orden dado como evidente de las cosas. Claro está, la tarea es difícil y exige coraje: es preciso realizar un corte a tiempo ya que el destiempo (akairós), en materia de salud y enfermedad, podría resultar fatal. Tal es la importancia de este "poco tiempo" donde se dirime una posibilidad práctica al servicio de hacer diferencia respecto de lo vigente. En estos términos lo relata Hipócrates en el capítulo V del Primer Libro de las Enfermedades, donde kairós y akairós aparecen en la siguiente traducción ${ }^{22}$, mencionados a la manera de "momento propicio" y "contratiempo" o "destiempo", respectivamente:

Los momentos propicios para actuar son, para decirlo de una vez por todas, numerosos y de toda clase en medicina, como lo prueban las enfermedades, las afecciones y sus tratamientos. Los momentos más fugitivos son aquellos en los que es preciso socorrer a los enfermos que desfallecen, que no pueden orinar o defecar, o se ahogan, o cuando es preciso asistir a una mujer que da a luz o que aborta, casos de este tipo. Estos momentos son fugitivos, y no alcanza tan sólo con intervenir, ya que si se interviene un poco más tarde, un poco más tarde, probablemente la mayoría de estos pacientes ya hayan muerto. [...] Hay casos en los que se pierde el momento de actuar. Lo que debió ser tratado por la mañana, si es tratado al mediodía, es tratado a contratiempo; a contratiempo, en este sentido el mal empeora

22 Para esta interpretación nos basamos en el estudio filológico de la traducción del Corpus realizado por R. Wittern (1974), retomado por Monique Trédé (1992 184-185). 
porque el tratamiento no se ha hecho cuando se debía. (...)

En tales casos, se cura a destiempo ${ }^{23}$.

El par kairos/akairos funciona así como criterio práctico frente a la decisividad reclamada por un actuar "crítico" en el tiempo. Así, este "momento crítico" busca, en un horizonte sin certezas donde reposar sus previsiones, "' actuar en el "momento justo" para reequilibrar lo vitalmente saludable. Kairos, krinein... la krisis de la enfermedad solicita la justeza de una precisión que no admite contratiempos.

En esta configuración problemática, entonces, la crisis es la figura de un pivote en tiempo presente que, frente a las expectaciones de futuro, no ofrece plan a seguir, pero que sin embargo exige actuar ahora. Es un punto de clivaje del tiempo que, aun con poco tiempo, hace advenir lo que todavía no puede ver, y lo que aún no llega a prescribir. Kairós habilitando una temporalidad específica para krisis, aquí viene a nombrar lo que en una visión de conjunto se mostraba imposible de aprehender, pero que sin embargo puede, efectivamente, ser asido de otra manera. Asir de otra manera, es decir, captar, atrapar, aprovechar, sorprender, empuñar lo que Hipócrates había percibido en sus tensiones constitutivas: la crisis es lo que en cada ocasión debe ser tratado de otra manera.

\section{Hacia un estatuto epistémico activo de la crisis hoy}

Llegados a este punto, finalizaremos este recorrido analítico que nos ha llevado lejos en el tiempo, con el fin de poner en valor la semántica mayor, variable y abierta que ha habilitado respecto de la crisis. Marcaremos una pausa en un estudio que se quiere, en cambio, no suturado, sino capaz de sostener a su vez una apertura crítica. Por ello, estas palabras finales no son concluyentes, sino que permiten reposicionar los términos de una reflexión que deberá ser proseguida, cotejada: nuevamente interpelada.

23 La traducción es nuestra. 
En todo caso, podemos decir que el estudio genealógico de krisis, y del cortejo polisémico que la vincula a krasis, krino, kûno, kairós, que hemos ido resituando en este artículo, permite contribuir al trabajo de búsqueda de reposicionamientos categoriales, requerido por las perspectivas de la filosofía política contemporánea para la tarea crítica del presente. Ciertamente, la producción de saber en la que ella se inscribe, en el contexto de la naciente medicina hipocrática, no solo la obliga a partir de un diagnóstico de la multiformidad de la experiencia, de la diversidad de prácticas mezcladas que hacen a la coyuntura de una situación particular, también la obliga a sostener un diálogo en el que participan diversos registros: intuitivos, perceptivos, orales, disciplinarios. En esa circunstancialidad siempre históricamente situada, "crisis" indica el breve momento en el que ha de decidirse una acción: su "juicio" deviene así gesto activo, capaz de cortar la reproducción de la lógica de los repartos vigentes, decidiendo el provecho de una oportunidad también presente en este momento káirico y crítico del tiempo.

De esta manera, sostenemos que "crisis", de la mano de krisis, puede animarse a recuperar lo que hemos llamado su "estatuto epistémico activo" y reinvestir las posibilidades críticas del diagnóstico de lo actual. Crisis que, definitivamente, munida de esta fuerza, podría desasirse de la nulidad temporal de su régimen presentista y reelaborarse en cambio cual práctica de aisthesis, mediante un saber mensurable y perceptivo, móvil y sintiente de sus prácticas (del sufrimiento que hablar de crisis implica). Crisis que, aun si su facultad bifurcativa del tiempo no le permita anticipar ni dominar el curso de los acontecimientos, es portadora de un saber que sabe que, con todo y a pesar de todo, aquí y ahora debe actuar. Esa es su urgencia.

Probablemente, para tomar distancia y estar en grado de interpelar los desafíos que la crisis del diagnóstico de nuestro presente sigue exigiendo, sea útil genealogizar y aprovechar la ampliación de la mirada que los anacronismos históricos pueden tensar con nuestra actualidad. Si permitimos esta tensión polisémica y esta apertura de pensamiento, sin duda el antiguo mundo griego ofrece un cortejo semántico cuya fuerza experiencial puede reavivar nuestro entendi- 
miento actual de la crisis de nuestro presente, exigiéndole el retorno de su capacidad actuante.

\section{Bibliografía}

Benveniste, Émile. Le vocabulaire des institutions indo-européennes. Paris: Éditions Minuit, 1969.

Benjamin, Walter. Thesis on the concept of history. Selected Writings Volume 4 1938-1940. England: The Belknap Press of Harvard University Press. Cambridge, Massachusetts and London, 2003.

Cassin, Barbara (comp.). Vocabulaire européen des philosophies: Dictionnaire des Intraduisibles. Paris: Éditions du Seuil, 2004.

Demócrito. "Máximas", en Fragmentos Presocráticos: de Tales a Demócrito. Buenos Aires: Alianza, 2008.

Esposito, Roberto. Inmunitas. Protección y negación de la vida. Buenos Aires: Amorrortu, 2005.

Foucault, Michel. Les mots et les choses. Une archéologie des Sciences Humaines. Paris: Gallimard, 1966.

Foucault, Michel. Nietzsche, la généalogie, I'histoire. Hommage à Jean Hyppolite. Paris: P.U.F., 1971.

Foucault, Michel (1984). Le courage de la vérité. Le gouvernement de soi et des autres II. Cours au Collège de France 1983-1984. Paris: Seuil, Gallimard, 2009.

Foucault, Michel (1984b). "L'éthique du souci de soi comme pratique de la liberté" (Entretien avec H. Becker, R. Fornet-Betancourt, A. Gomez-Müller, 20 janvier 1984). Dits et Écrits, Vol. 2, Paris: Quarto Gallimard, 2001. 1527-1549.

Gallet, Bernard. Recherches sur kairos et l'ambiguité dans la poésie de Pindare. Bordeaux: Presses Universitaires de Bordeaux, 1990.

Hartog, François. Régimes d'historicité. Présentisme et expérience du temps.

Paris: Seuil, 2003.

Hartog, François. «Temps et histoire. Comment écrire l'histoire de France?". Annales Hss, novembre-décembre (1995/6): 1219-1236.

Heinimann, Felix. "Mass, Gewicht und Zahl". Mus. Helv., 33 (1975): 79-133. 
Hipócrates. Corpus Hipocraticum, 420-350 a. C, Oeuvres Complètes d'Hippocrate, Émile Littré, Traduction Nouvelle. 21 vols. Paris: Baillière, Librairie de I'Académie Royale de Médicine, 1839.

Jaeger, Werner. Paideia. Los ideales de la cultura griega. México: FCE, 1957.

Lazzarato, Maurizio. Políticas del acontecimiento. Buenos Aires: Tinta Limón, 2006.

Liddell, Henry Georges y Scott, Robert. (Comp.). A Greek-English Lexicon. Oxford: Clarendon Press, 1968.

Marcuse, Herbert. One-Dimensional Man: Studies in the Ideology of Advanced Industrial Society. Boston: Beacon Press, 1954.

Nora, Pierre. "La mémoire collective". La nouvelle histoire, Jacques Le Goff (dir.). Paris: Retz-CEPL, 1978. 398-401.

Onians, John. Arte y pensamiento en la época helenística: la visión griega del mundo (350 A.C. - 50 A.C.). Barcelona: Editorial Alianza, 1996.

Robert, F. "La prognose hippocratique dans les livres V et VII des Épidemies". Le monde grec (Hommages à Claire Préaux), Jean Bingen, Guy Cambier y Georges Nachtergael, eds. Bruselas: Éditions de I'Université de Bruxelles, 1975. 257-270.

Trédé, Monique. Kairos. L'à-propos et l'occasion (Le mot et la notion, d'Homère à la fin du IV siècle avant J.-C.). París: Éditions Klincksieck, 1992.

Virno, Paolo. El recuerdo del presente. Ensayo sobre el tiempo histórico. Buenos Aires: Paidós, 2003.

Wittern, Renate. Die hippokratische Schrift De morbis I, Ausgabe, Übersetzung und Erläuterungen, New York: Hildeshem, 1974. 